\title{
Mary F. Hill \& Martin Thrupp (eds): The Professional Practice of Teaching in New Zealand (6th Edition)
}

\section{Cengage Learning Australia, Melbourne, 2020, ISBN 9780170416771, Edition 6, 352 pages}

\section{Noeline Wright ${ }^{1}$}

Received: 19 March 2020 / Accepted: 26 March 2020 / Published online: 29 March 2020

(c) New Zealand Association for Research in Education 2020

The Sixth Edition of The Professional Practice of Teaching in New Zealand (Eds Mary F. Hill and Martin Thrupp) updates this long standing initial teacher education (ITE) text. It has a new look and the chapters convey a contemporary, inviting impression.

The inviting look to the text makes this academic text attractive to those who want to be teachers. The clarity of layout is not always easy to achieve. Academic texts often feel impenetrable and dry; they're easier to ignore than read. To that end, this edited book models appropriate professional practice. It begins with a 'guide to the text' page, thus orientating readers to the structure and purpose of various elements throughout the chapters. Making unfamiliar, academic text inviting, can be half the battle for anyone reading unfamiliar text, and this book addresses such possibilities with its clear layout and colour coding.

The chapters are organised in what seem to be groups of topics: They begin with chapters about the teacher self, before addressing issues of classrooms-curriculum assessment, behaviour, resources and tools for learning, cultural and relational practices, understanding flexible learning spaces and pedagogy. The last section addresses issues beyond a classroom-critical awareness of leadership, policy, politics-before concluding with a chapter about taking on one's first teaching role. Together, the chapters offer a coherent trajectory common to ITE programmes in New Zealand.

Abbiss's introductory chapter explores questions like 'What sort of teacher identity do I want to have or have?' thus introducing the reader to the flavour and context of the book. Both Abbiss's and Buntting's chapters express complex ideas in disarmingly simple and accessible ways. Both authors pose questions for readers as they become more aware of learning theories and what these mean in classrooms.

Noeline Wright

n.wright@waikato.ac.nz

1 School of Education, University of Waikato, Private Bag 3105, Hamilton 3240, New Zealand 
These chapters segue into the third chapter, which concerns itself with aspects of belonging, agency, cohesion and diversity through the concept of ako, which brings the learner and teacher together within a community. There is a strong focus on relational practices, helpfully summarised in a table (Fig. 3.1). The chapter ends by acknowledging that reciprocal, relational practices come with tensions that can be hard won, requiring considerable time and effort.

Building any kind of relationship involves dialogue. Sandretto's chapter considers the role and value of dialogue as a pedagogical and critical thinking tool in helping both students and teachers 'figure things out' (p. 86). As with other chapters, this one offers scenarios. These give insight into how dialogue can shape learners' deeper thinking processes.

These early chapters are aware of differences between primary and secondary school classroom dynamics and conditions. However, the following chapter assumes too much sameness as it uses primary schooling contexts to illustrate curriculum planning, even though it purports to also relate to Years 9-10. Structural secondary school impediments of timetables, ability stratification and separate subjects may militate against the principles of flexible grouping advocated here. That is not to say this chapter does not contain solid ideas that might be used beyond primary settings, especially when discussing ideas about learning. However, applying the kinds of positive and evidence-informed ideas Sewell, Smith and Kennedy offer, especially in using Figs. 5.1 and 5.2 as models for planning, may not connect with many secondary experiences.

There is a natural segue from planning to assessment. Examples from a range of school contexts suggest various methods for assessment, such as judging proximity to intended outcomes, as well as progress towards learning goals. Hill's chapter includes feedback and feedforward, goal setting, and self reflection, arguing that student agency is a key intention of assessment for learning. To that end, the chapter offers ideas about the how, what and why of different kinds of methods associated with assessment and evaluation.

'Assessment' can also be what we do about ourselves - and so this next chapter centred on Teaching as Inquiry, is the focus. Self reflection in learning applies to teachers' practices. Sinnema and Aitken address the nature of Teaching as Inquiry by comparing it with other forms of inquiry. Their chapter offers readers an accessible introduction to this framework, centring attention on teachers as reflective practitioners who are keen to develop greater insight into their practices. The authors view teachers as wanting to support learners and learning, while also testing the value of the learning strategies they provide for students in meeting intended learning outcomes. Sinnema and Aitken's aim is to promote "more rigorous and higher-quality inquiries..[about] student learning ... [fostering] better learning for teachers about their practice" (p. 147).

While Teaching as Inquiry is often focused on learning outcomes, it has the potential to be applied to examining how to manage classroom behaviour. The proximity of the next chapter's focus suggests potential links about how teachers might reflect on their classroom behaviour management approaches. Kecskemeti and Hamilton address typical classroom behaviours, using scenarios to explain key concepts likely to establish and sustain respectful classroom relationships. They offer helpful 
suggestions in dealing with both short-term disruptions and longer term physical and psychological safety. They also acknowledge the complexity of dealing with unruly, disruptive or aggressive behaviours that might affect a teacher's and students' safety.

Berryman and Eley's chapter (Chapter 9) firmly centres attention on "Māori enjoying and achieving education success as Māori" (p. 171) in a chapter addressing the contributions Māori learners' experiences have on ways we understand the value and role culture plays in classrooms. The chapter decisively underscores the persistent 'education debt' for Māori learners, questioning root causes (systemic failure and/or cultural deficit). The authors demonstrate the importance of evidenceinformed and reflective practices linking with Inquiry to examine pedagogical and professional actions. The aim is to develop and sustain strong relational connections between and with students and whanau. Legacies of colonisation are front and centre.

Given the advice from Berryman and Eley, Chapter 10 extends the conceptual and actual realm of a teacher's role to addressing diversity and identity, or 'differentness' (p. 195). Hochstrasser, Fickel and Guerin address differentness in relation to 'priority learners' and what this means in classroom contexts, particularly before students reach high school. They also explore transgender identities, various developmental conditions students cope with, and the value of strong classroom relationships. The link between this and the previous chapter is clear, as both invoke culturally responsive pedagogy and its role in building strong and positive classroom dynamics, predicated on teachers recognising "diversity as a strength" (p. 206).

Chapter 11 builds on aspects of diversity and inclusion by speculating on the role of spaces in learning. Benade's snapshot of different types of learning contexts in New Zealand, establishes a focus on new kinds of learning spaces and the flexibility of the furniture within them. He argues that new types of spaces trigger a rethink about what goes on inside them, suggesting that through integrated subjects, learning "draws on real life, [and] is therefore unforgettable" (p. 224). Such integration is more easily achieved when the geography of spaces afford more flexible pedagogical design, thus mimicking real life problem solving. On the other hand, traditional single cell classroom geographies seldom foster such cross curricular collaborations. Benade offers a nuanced perspective for those new to the profession.

One of the key drivers for new types of learning spaces has been the disruptive effects of digital technologies in the education sphere. Forbes and Earl Rinehart's chapter discusses key ideas about the role digital technologies play in this century's learning contexts. The chapter neatly encapsulates some of the broad issuesaccess, screen time, online safety for example-while firmly arguing that digital learning is about connections. This acknowledges "the human dimension of technology" (p. 251) and makes clear that a teacher's role is to plan for deliberate and purposeful uses of digital technologies in classrooms to achieve specific learning outcomes. Perhaps this chapter's ideas about connection now have greater resonance in a time of Covid-19 lockdown.

The next three chapters (13-15) address issues of policy: the creep of privatisation in education, teacher ethics and the politics of education. They form a neat core of chapters that move the focus from the classroom to the national context and beyond. Just as the first few chapters centred attention on the teacher, and the ones 
in the middle addressed classrooms and students, now we read about Big Picture issues; the kind that mould how teachers, classrooms and students operate. As a set, they are key chapters for neophyte teachers.

Take Powell's focus on privatisation for example. Through drawing on examples of privatised programmes for primary schools, he outlines some inroads that private companies have made into teaching and learning contexts when they present solutions for overcommitted teachers. This is not to say that such companies are reprehensible, but their motives are seldom altruistic or focused on learning. Powell suggests that such companies may serve to devalue a teacher's role.

Perhaps it is no accident that the next chapter is about professional ethics. O'Neill's chapter grapples with the statutory framework in Aotearoa. His scenarios offer plenty of grey areas and no easy answers. In my view, this chapter is crucial for developing ITE students' ethical knowledge and appreciation of such thorny nuance and greyness.

The final chapter in this trio positions teachers as needing to keep a critical educational eye on research and politics. Thrupp argues that there is a difference between those who focus on solving problems, compared with those who seek to understand the problem first. The latter, he argues, have a critical eye. Thrupp argues that assessments and notions about what constitutes effective teachers are highly contested, using the demise of National Standards to argue his position.

The final chapter, fittingly, returns to a focus on the individual: how one moves into the profession. Ferrier-Kerr outlines and summarises key ideas from previous chapters, showing how they link to someone taking on their first teaching role. Her chapter, like earlier chapters, includes scenarios of actual practice when teachers have taken on their first teaching role. The chapter concludes the book.

Overall, I enjoyed reading this text. It forms a cohesive whole, yet individual chapters can stand alone and offer insight and opportunities for debate and discussion. Clear prose is a hallmark of the text as a whole, and I appreciated this aim of simplicity. I know how difficult it can be to make complex ideas accessible to read simply and clearly. The chapters overall, do a fine job in achieving it, and students encouraged to read chapters in this text as part of the ITE, will be well served.

Publisher's Note Springer Nature remains neutral with regard to jurisdictional claims in published maps and institutional affiliations. 